\title{
Alice's Anima: The Obligation of a Transmedia Reading
} Fernanda Bonacho

Escola Superior de Comunicação Social, Portugal

doi: 10.7358/ijtl-2015-001-bona

fbonacho@gmail.com

\begin{abstract}
This paper suggests an analysis of "Inanimate Alice" by Kate Pullinger as an example of a transmedia narrative that triggers a new reading experience whilst proposing a literary alterity between reading and performance. Narrative experiences that elect the visual plasticity, interchanging games and tactility as drivers of the creative process are not new. Yet, narrative experiences, which have been created in the gap between reality and fiction, have found on the digital realm the ideal environment to multiple hybrid experiences. A critical analysis of this digital fiction tries to illustrate how literary art finds its space and time in a metamorphosed continuum and crafts experience with a transmedia reading. All the multimedia hybrids with which this digital literary work engages, challenge readers to interpret different signals and poetic structures that also embed game rhetoric. Yet, among Alice's playful world and cognitive dissonance, meaning is only found and reading happens when time, space and attention are available to configure the story and interpret significance. Transmedia literacies give life to this experience of online reading when they focus and draw attention not to a simple new behaviour or a single new practice, but to different objective and subjective value forms.
\end{abstract}

Keywords: transmedia reading; literary alterity; transmedia narrative; multimedia; digital fiction; narrative experience; Intimate Alic.

\section{INTRODUCTION}

"Inanimate Alice" ${ }^{1}$ (IA) by Kate Pullinger, Chris Joseph and Ian Harper is an example of a transmedia narrative that triggers a new reading experience whilst proposing a literary alterity between reading and performance. Narra-

1 http://www.inanimatealice.com/. 
tive experiences, such as this one, which elect the visual plasticity, interchanging games and tactility as drivers of the creative process are not new. Yet, narrative experiences, which have been created in the gap between reality and fiction, have found on the digital realm the perfect environment to multiple hybrid experiences. Henry Jenkins describes this type of transmedia storytelling as a process where "integral elements of a fiction get dispersed systematically across multiple delivery channels for the purpose of creating a unified and coordinated entertainment experience." Furthermore, he adds that "ideally, each medium makes it own unique contribution to the unfolding of the story" (Jenkins 2011). In fact, Inanimate Alice is a transmedia project because personifies each one of these characteristics being designed over time and on multiple platforms (see Figure 1). Bearing in mind Walter Benjamin's concept of Erlebnis and Erfabrung this paper tries to demonstrate how literary art finds its space and time in a metamorphosed continuum only activated by an engaged reader, who must be able to transform a moment of reading into an experience of reading in Benjamin's terms:

Historically, the various modes of communication have competed with one another. The replacement of the older narration by information, of information by sensation, reflects the increasing atrophy of experience. [...] This is the nature of something lived through (Erlenis) to which the reader has [to give] the weight of an experience (Erfahrung). (Benjamin 1991, 190)

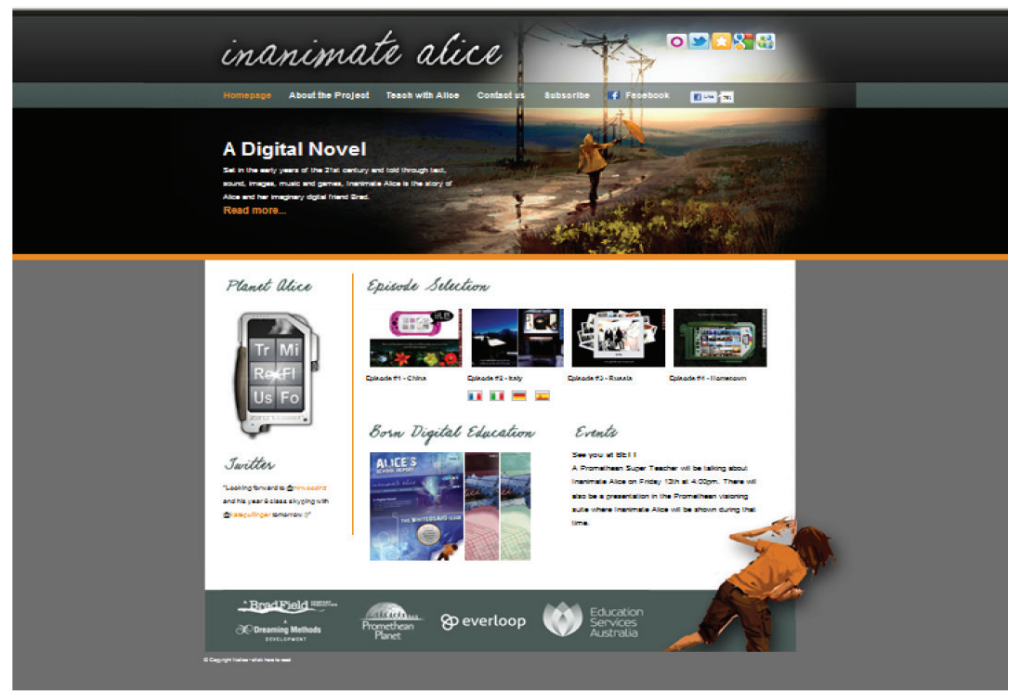

Figure 1 - Inanimate Alice (Homepage). 
All the multimedia hybrids, which Alice presents, challenge readers to interpret different signals and poetic structures whilst facing a certain "atrophy of experience". However among a cognitive dissonance, meaning can be found if a set of transmedia literacies, or transliteracies, are available: (narrative literacy, multimodal literacy, digital literacy, media literacy, visual literacy, information literacy or game literacy). All literacies are constructive within this experience of online reading because as a transliterate practice they are able to focus and draw attention not to a simple new behaviour or a single new practice, but to different circumstances that invite different objective and subjective value forms.

Running with Flash Player, the 4 available episodes (set in China, Italy, Russia and England) connect technologies, languages, cultures and different generations. After Alice's journey starts, there are always new storylines appearing elsewhere providing more details and insights, stirring the plot through surprising developments. Meanwhile, readers are also encouraged to collaborate and develop episodes of their own, either filling in the gaps or developing new strands. IA's narrative is central to a story world whose multimodal texts include sound, image, written text, video and gaming elements, and without experiencing all those components, we miss the whole story.

\section{2. Playing Alice}

Inanimate Alice's environment of simulation reminds any computer game. Originally written for a computer and to be read in a computer, this is a digitally born piece with many game elements aligned with sound and music effects. They simulate a parallel world where games and enigmas are part of the narrative and engage directly in its progress. Yet, there is a significant difference between this digital fiction and those electronic games: whereas in games we need to previously know the rules to be able to play, in this electronic piece, we must play first to be able to continue reading and understand the story. (Figure 2)

\section{This story uses images, text, and sound; please turn on the sound on your computer.}

Use your mouse and click on the arrows $\gg$ to move forward.

Sometimes you may need to perform an action for the story to continue -

move the mouse and click on the relevant image.

Click on the hand to explore the interactive sections; you can choose which direction you want to go.

You can also use the icons on the right-hand side to return to earlier sections.

The story takes around thirty minutes to view.

$\gg$

Figure 2 - Inanimate Alice (Episode 4: Hometown).

International Journal of Transmedia Literacy - 1.1 - December 2015

http://www.ledonline.it/transmedialiteracy/ 
Katheryne Hayles said that "with games the user interprets in order to configure, whereas in works whose primary interest is narrative, the user configures in order to interpret" (Hayles 2008, 8). Actually, the game elements are added by Alice throughout the story and, if on the one hand, they coexist and contribute for the main character's development; on the other, they also dispute the reader's attention. To be able to read IA we need to fully grasp "a deep and hyper attention" that this game literacy of logical, strategic thinking and problem solving requires (Hayles 2008). There is the possibility to read with or without playing the game because, according to the authors, it was very clear that the public is always divided between those who enjoy playing as they read and those who do not (Pullinger 2011). However, the truth is that there are moments when readers have necessarily to play and participate in a "playful reading" because otherwise the narrative will not progress and Alice will not continue her adventure.

Being a putative game designer who creates and directs her electronic device, Alice personifies the engaged reader giving life and controlling (more intensively in each episode) the actions of characters and working as the animator and interpreter of Alice's own adventures. The need for navigation, evaluation and creation of meaning using digital technologies is part of a digital literacy that this transmedia piece uninterruptedly claims.

We never see or listen to Alice nor anyone, except through their words displayed on the screen, and except for Brad's voice - Alice's virtual and imaginary best friend. The strong presence of electronic games in Alice's life allows her to create Brad (her only friend until she turns 14) who lives inside her baxi - an electronic device which takes photographs, makes videos, plays music, makes phone calls, accesses the web, etc. In this multimedia electronic device have converged different applications that allow Alice to describe her adventures, to draw, to paint, to make drafts and to be informed. (Figure 3)

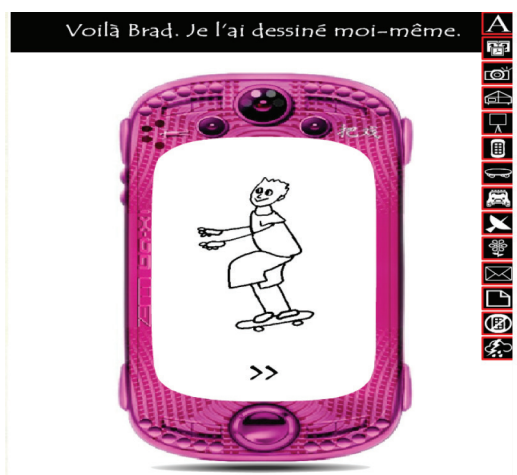

Figure 3 -Inanimate Alice, Episode 1: China (Allumer Console). 
Yet, more interesting than all those digital activities, it is the strong influence that this baxi has over Alice and the symbolic meaning it assembles as an inherent part of her memory and identity. The baxi is a powerful driver when repeatedly triggers Alice's storytelling - the constant invitation to interact with the game prompts the narrative and obliges the reader to deal with a wide range of data to follow the gist, solve problems and make decisions. It is, actually, inside this baxi that Alice finds her favorite digital creation - Brad, who the one who supports her in the most difficult situations throughout the story. In some particular moments, the game designer's function is even substituted and it is the virtual Brad who controls Alice: "I heard Brad's voice in my head saying 'Go that way.' And so I say to my Mum, 'Go that way', and she does." (Inanimate Alice, Episode 1: China (Brad). This virtual amplification escorts this girl's growth: like a puppet on the strings, Alice is influenced by her peers, directed by Brad and even by the reader.

\section{ANIMA}

The significance of Inanimate Alice is built across multiple media and modes of communication and there is a constant invitation to search meaning across different elements of the story. This multimodal literacy is necessary, for example in episode 3, when we confirm the importance of how sound, image and written text are defined and filtered through Alice's perspective (see Figure 4).

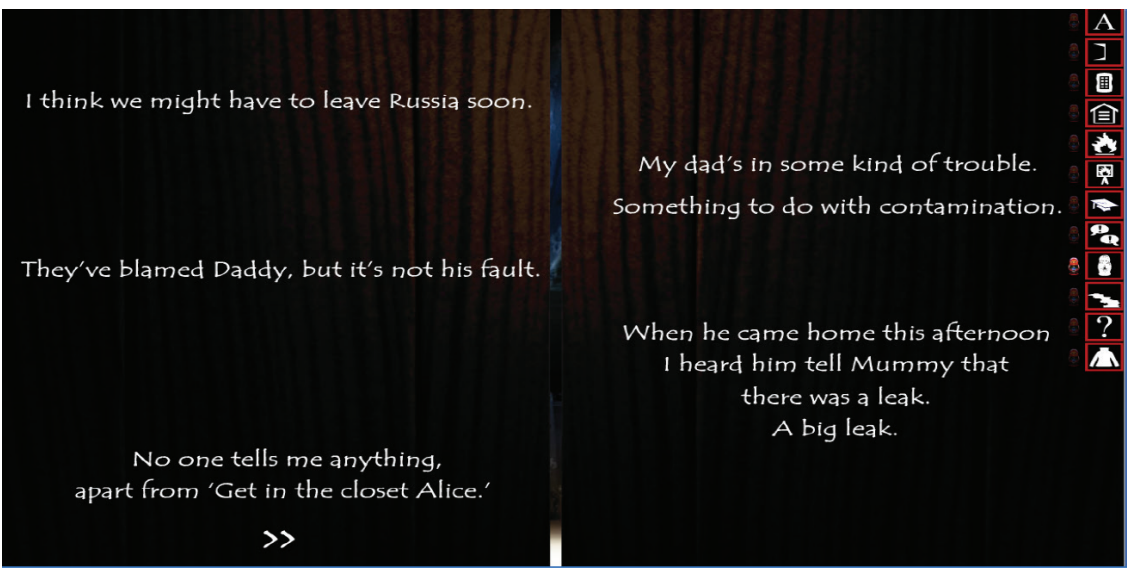

Figure 4 - Inanimate Alice, Episode 3: Russia (Trouble). 
Alice is hidden inside a closet, listening to her father arguing with the Russians, and the words start showing on the screen, coming from a semi opened door as if they are hitting Alice. The effects of these strategies, that include different modal elements, support the unraveling the story in a rather cinematic style. The same happens when we see the words coming in and out of the scene to underline what is happening in episode 4. In the sequence "What happened", there is a moment when Alice's friends run away and leave her alone in danger hanging from some stairs for a while, until they come back again. The words leave the front scene to go behind a wall but not completely outside the photograph. Whilst demonstrating the direction they take, the movements of the words underline the importance of the open and empty space left on the photograph. Alice recognizes she is not alone and that her ANIMA comes actually from within. Her friends, who may not be always (publicly) present in the photo, are real and will arrive to support her in the last moment.

IA's digital fiction has many moments like this where meaning is built from an engaged use of graphic, linguistic and behavioral texts. Sometimes, the use of a certain movement and format underlines the verbal context, but sometimes it goes further, as in the given examples. The value of transmedia literacies in this fiction is enormous yet always dependent on how we grasp such digital experience whilst reading these media presences or absences.

Now, will this graphic display have similarities with some mise-en-page techniques of traditional narratives? Actually, Inanimate Alice also presents a wide range of traditional poetic strategies to structure the story. Yet, the need for a transmedia literacy that enables the articulation of different levels of language - between verbal (written words) and non-verbal (image, video, sound, games) - is necessary to produce multimodal meaning-making in a multimedia experience.

Alice's narrative complexity grows as the main character gets older and substitutes the attention she dedicates to her parents Ming and John (first episode being eight years old) to concentrate on school, her friends and on the games she creates with her baxi. The interactivity of the story becomes more complex in each episode and the quantity of verbal text diminishes, whilst Alice learns to produce more dynamic and interesting games. The level of interaction with the reader increases, the electronic device turns more complex and even the sound we hear is not a mere soundtrack but a proactive sound that complements and amplifies conflicts and the episode's problem solving. Meanwhile, Alice improves her writing, art and design skills as the words selected, the type of letter, music and all the surroundings become gradually more sophisticated and adapted to her age (from being eight to being fourteen). In episode 4 (England), for example, the atmosphere is very tense, all images are rather dark and the music tunes a frenetic and yawning sound. Here, the feeling of 
danger is lived in a different way: being fourteen, it is Alice's own actions that take her to problematic situations, which then she manages to solve without her parents' help.

Furthermore, it is also important to note the frequent interruption of the narrative sequence that feeds the complexity of this fictional work. In episode 4 , but also in episode 2 and 3 , there are several references to previous episodes and details of Alice's past among multiple modes of text that integrate and clarify details, but in a mixed and deeply diversified way with voices, maps, photographs, etc. The random interpellation of these elements is determining not only to characterize the main character but also to add up narrative diversity to the piece. Inanimate Alice's core world demands a critical narrative literacy able to "destructure" and "restructure" the text in order to develop a critical understanding of the plot.

\section{READING ALTERITY}

The final aspect that makes this literary piece an example of a transmedia experience is its self-referentiality in "iStories". (Figure 5)
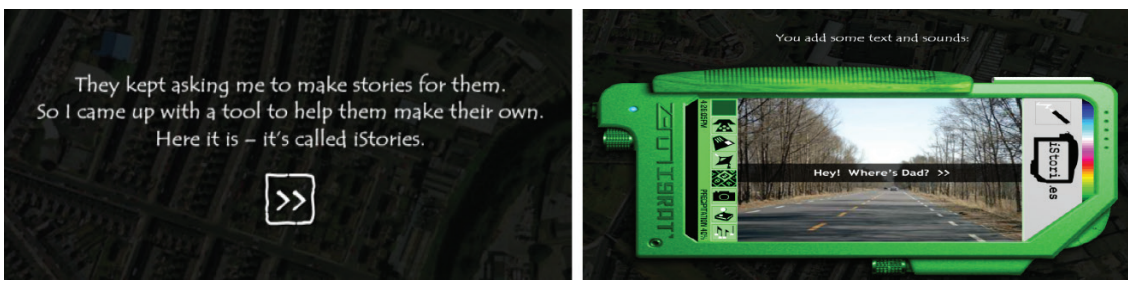

Figure 5 - Inanimate Alice, Episode 4: Hometown (Hometown).

iStories is an electronic application that helps Alice's friends (fictional characters and us readers) to produce stories by choosing photographs and adding verbal text and sound to the plot. Since it has been created in 2005, Inanimate Alice has been explored as a digital work in a wide range of areas $^{2}$, namely as a pedagogical instrument with the project Teach with Alice. (Figure 6)

2 Inanimate Alice written by Kate Pullinger, with the digital art of Chris Joseph and the production of Ian Harper has been exhibited as a digital piece in different countries, prize awarded in some movies festival and also integrated in the I and II Electronic Literature Collection: European Year of Intercultural Dialogue 2008, http://www.interculturaldialogue2008.eu [English, Spanish, French, Italian and German versions of Inanimate Alice, episodes 1-3]; IBM Prize for New Media, 20th Stuttgarter Filmwinter, Estu-

International Journal of Transmedia Literacy - 1.1 - December 2015

http://www.ledonline.it/transmedialiteracy/ 


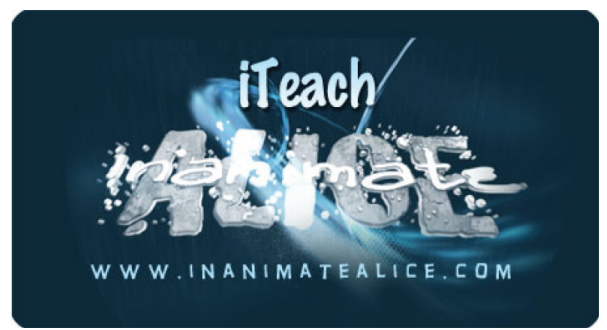

Figure 6-Teach with Alice Badge ${ }^{3}$.

This project has taken iStories seriously enough to become a successful free online application for many teenagers from all over the world, who have created brand new IA adventures. As part of this transmedia educational project, students are invited to read but also to collaborate in a multimedia production, developing creative writing pieces in their classrooms and imagining new adventures for Alice and Brad, by adding photographs, sound, games, drawings, etc. The New Media professor and researcher Jessica Laccetti, from Alberta University, underlines the importance of these projects for the young generation. She reminds that most students are already transliterate and familiar to multimodal environments of the online world, therefore, new media narratives like Inanimate Alice should be considered "prime pedagogical material" (Laccetti 2011).

In some way, iStories and the whole Inanimate Alice experiences use the same languages of the transmedia universe, which can only make sense if there is a competent reader to collaborate, select and articulate the available digital and non digital components in a meaningful way.

I show my friends stuff I've made on my player - stories and music mostly.

They kept asking me to make stories for them.

So I came up with a tool to help them make their own.

It's called iStories.

You choose a few of your favourite photos

You add some text:

[...]

And some music:

garda, Alemanha [Inanimate Alice, Episode 1: China]; 2008 CULTURAS Intercultural Dialogue Awards, Madrid, Espanha [Alicia Inanimada, Episodio 1: China]; http://collection.eliterature.org/1/works/pullinger_babel_inanimate_alice_episode_1_china.html; http://collection.eliterature.org/2/works/pullinger_ inanimatealice4.html; Best Web Site for Teaching and Learning 2012 / AASL (American Association of School Libraries) http://www.inanimatealice.edu.au/teach.html.

3 http://www.inanimatealice.com/share.html. 
And - boom! - you have a story!

Inanimate Alice. Episode 4: Hometown (My Project).

Inanimate Alice's trasmedia novel may have this boom effect in the reader, with a narrative universe that may excite and overwhelm teenagers due to its semantic amplitude. Yet, reading will always be incomplete if it does not overcome superficial and immediate transmedia clamor. Only if we are able to simultaneously deal with those different literacies, may the reading experience transform, decipher and interpret the different messages and, preferably, find and create new ones.

Alice requires the constant presence and collaboration of the reader to a different reading experiment: not only to read, watch and play but to experiment an inclusive phenomenological practice. As a piece of electronic literature, this transmedia fiction works as an allegory to a wide range of complexities and ambiguities of today's digital world that end up being read and animated through the path of transmedia, or in the end, our other self.

\section{REFERENCES}

Benjamin, Walter. 1992. Illuminations. London: Fontana Press.

Hayles, Katherine. 2008. Electronic Literature: New Horizons for the Literary. Notre Dame, Indiana: University of Notre Dame.

Jenkins, Henry. 2011. "Transmedia 202: Further Reflections." The Official Weblog of Henry Jenkins. Last access 14 March, 2014. URL: http://henryjenkins. org/2011/08/defining_transmedia_further_re.html.

Laccetti,Jessica.2011. "TeacherTraining." InanimateAlice:SchoolReport3,p.6.Lastaccess 14 March, 2014. URL http://issuu.com/inanimatealice/docs/school_report_3.

Pullinger, Kate. 2005. Inanimate Alice. Last access 14 March 2014. URL: http://www. inanimatealice.com.

Pullinger, Kate. 2011. "Live webchat: Kate Pullinger." The Guardian, 1st July 2011. Last access 14 March, 2014. URL http://www.theguardian.com/books/ booksblog/2011/jun/29/live-webchat-kate-pullinger. 